BMC

Genomics

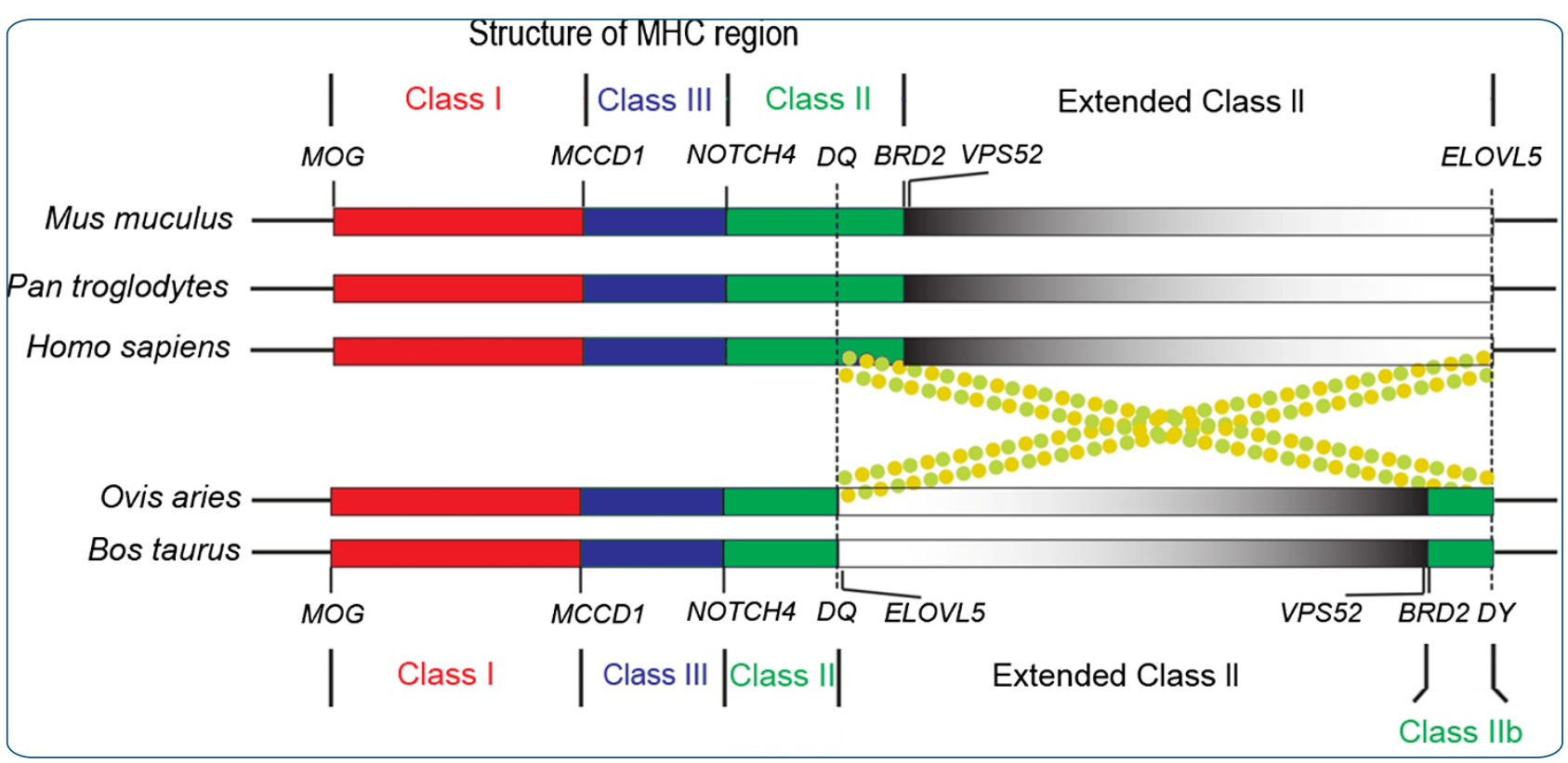

\title{
A physical map of a BAC clone contig covering the entire autosome insertion between ovine MHC Class Ila and IIb
}

Li et al. 


\title{
A physical map of a BAC clone contig covering the entire autosome insertion between ovine MHC Class Ila and IIb
}

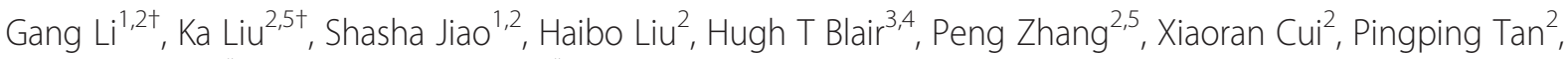
Jianfeng Gao ${ }^{1,4^{*}}$ and Runlin Z Ma $2,4,5,6^{*}$

\begin{abstract}
Background: The ovine Major Histocompatibility Complex (MHC) harbors genes involved in overall resistance/ susceptibility of the host to infectious diseases. Compared to human and mouse, the ovine MHC is interrupted by a large piece of autosome insertion via a hypothetical chromosome inversion that constitutes $\sim 25 \%$ of ovine chromosome 20. The evolutionary consequence of such an inversion and an insertion (inversion/insertion) in relation to MHC function remains unknown. We previously constructed a BAC clone physical map for the ovine MHC exclusive of the insertion region. Here we report the construction of a high-density physical map covering the autosome insertion in order to address the question of what the inversion/insertion had to do with ruminants during the MHC evolution.

Results: A total of 119 pairs of comparative bovine oligo primers were utilized to screen an ovine BAC library for positive clones and the orders and overlapping relationships of the identified clones were determined by DNA fingerprinting, BAC-end sequencing, and sequence-specific PCR. A total of 368 positive BAC clones were identified and 108 of the effective clones were ordered into an overlapping BAC contig to cover the consensus region between ovine MHC class Ila and IIb. Therefore, a continuous physical map covering the entire ovine autosome inversion/insertion region was successfully constructed. The map confirmed the bovine sequence assembly for the same homologous region. The DNA sequences of 185 BAC-ends have been deposited into NCBI database with the access numbers HR309252 through HR309068, corresponding to dbGSS ID 30164010 through 30163826.
\end{abstract}

Conclusions: We have constructed a high-density BAC clone physical map for the ovine autosome inversion/ insertion between the MHC class Ila and Ilb. The entire ovine MHC region is now fully covered by a continuous BAC clone contig. The physical map we generated will facilitate MHC functional studies in the ovine, as well as the comparative MHC evolution in ruminants.

Keywords: Ovine, MHC, OLA, Physical map, BAC, Comparative mapping

\footnotetext{
*Correspondence: jianfengg@shzu.edu.cn; rlma@genetics.ac.cn

${ }^{\dagger}$ Equal contributors

${ }^{1}$ School of Life Sciences, Shihezi University, Xinjiang 832003, China

${ }^{4}$ Joint Research Center for Sheep Breeding and Developmental Biology,

IGDB-Massey University, Massey, New Zealand

Full list of author information is available at the end of the article
} 


\section{Background}

The mammalian Major Histocompatibility Complex (MHC) harbors genes involved in overall resistance/susceptibility of animals to infectious pathogens, including viral, bacterial, internal and external parasites. Pathogens serve as sources of selection pressure to their host animals, and the hosts are forced to develop effective strategies to fight against the pathogens in various environments. Such co-evolutionary struggles may have left distinct marks in the genome of each species involved, and mammalian MHC regions have been shaped into clusters of immunological gene families by such host-pathogen interactions, probably via functional gene duplications [1-3]. The implications of ovine MHC molecules in providing protection against pathogens [48] and the associated structures of the artiodactyl's $\mathrm{MHC}$ region in general have led to a number of studies into the sheep MHC [9-15].

The ovine MHC, also called ovine leukocyte antigen (OLA), is located on the long arm of ovine chromosome 20 (OAR 20q15-20q23) with a similar structure and organization to that of human and other mammals [16]. The literature shows that MHC genes play vital roles in resistance of animals to foot rot [17], parasites [9], and bovine leukemia virus [7]. To date, the majority of studies on the structure and organization of the ovine MHC have focused on the gene content and polymorphism of the class II region [18-23]. Although most loci in the sheep MHC are found to be homologous to their counterparts in the human MHC [12,21,24,25], there are significant differences. Examples of such differences include the $D P$ loci in human being replaced by $D Y$ in sheep $[19,21,26,27]$, and the number of $D Q A$ loci varying significantly among sheep breeds [20,22,28].

Compared to human and mouse, the structure of the sheep MHC is interrupted by a piece of $\sim 14 \mathrm{Mb}$ autosome insertion, possibly via a hypothetical chromosome inversion (inversion/insertion) in the class II region, similar to that of cattle [24,29-32]. The inversion/insertion constitutes $\sim 25 \%$ of ovine chromosome 20, which spliced the MHC class II region into IIa and IIb. The significance of such an insertion in relation to the ovine MHC functions remains unknown. The evolutionary consequence of such an event is also worthy of attention, because some of the ovine-specific MHC loci like $D Y$, and $D s b$ are located near the boundary region of the inversion/insertion. We previously constructed a physical map of BAC clone contigs covering the ovine MHC except the autosome insertion region [12,13], and a high accuracy sequence map of sheep OLA was accordingly constructed [14].

With the initial release of sheep whole genome reference sequences by the International Sheep Genomic Consortium (ISGC), much more genome sequence information is now accessible for functional and comparative studies [33]. Nevertheless, the sequence map would serve the research community even better if it is cross-referenced/checked for accuracy in DNA sequence and assembly, at least for some chromosome regions, by an alternative approach. In this regard, the detailed information is still not fully available for the gene structure, organization, and DNA sequence for the ovine chromosome region between OLA class IIa and IIb $[12,14,27]$.

In this paper, we describe the construction of a BAC physical map covering the entire autosome insertion between ovine MHC class IIa and IIb. Because ovine and bovine species share the consensus structure and organization in the entire MHC region [24,29-32], we used comparative approaches to screen a sheep BAC library with 119 bovine oligo nucleotide primers designed from the bovine genomic sequences for the consensus region. The order and overlapping relationship of the identified BAC clones were determined by DNA fingerprinting, BAC-end sequencing, and sequence-specific PCR. A total of 108 effective overlapping BAC clones were selected to fully cover the region between class IIa and IIb. The physical map we constructed will help to generate ovine MHC sequencing map with a high level of accuracy, which in turn will facilitate MHC functional and comparative MHC evolution studies in ruminants.

\section{Methods}

\section{Comparative design of oligo primers}

A BAC library was previously constructed using the genome DNA from a male Chinese merino sheep, with a total of 190,500 BAC clones and an average insert length of $133 \mathrm{~kb}[12,13]$. To screen the BAC library for positive clones in the target genome region between ovine MHC class IIa and IIb, we adapted a comparative strategy to design bovine oligo nucleotide primers using the bovine reference DNA sequences in the consensus genome region [34]. At the time this study was conducted, no sheep genomic sequence was publicly available for the genome region of our concern. Bovine DNA sequences of homologous genes, exon, intron, or partial STS sequences were acquired from the NCBI website (http:// www.ncbi.nlm.nih.gov/genome/sts/). Primers were designed along the bovine MHC region between class IIa and IIb, approximately $80-160 \mathrm{~kb}$ apart between two neighbor loci using the software Prime Primer 5.0 (Biosoft International, CA). A total of 119 bovine primer pairs were designed for screening the sheep genomic BAC library (Table 1).

\section{BAC library organization and screening}

To facilitate large scale PCR screening, all the 190,500 clones of the BAC library were organized into 3-dimensional BAC clone pools of plates, rows, and 
Table 1 Comparative bovine primers used for identification of the positive ovine BAC clones in the genome region between MHC Class Ila and IIb*

\begin{tabular}{|c|c|c|c|c|c|}
\hline Name & $\begin{array}{l}\text { Gene } \\
\text { symbol }\end{array}$ & Primer sequence $\left(5^{\prime} \rightarrow 3^{\prime}\right)$ & Product(bp) & $\begin{array}{l}\text { Bovine template } \\
\text { sequence }\end{array}$ & Positive OvineBAC clones \\
\hline \multirow[t]{2}{*}{ S001 } & \multirow[t]{2}{*}{ VPS52 } & F: ATCAATCAGACGATTCCCAACG & \multirow[t]{2}{*}{246} & \multirow[t]{2}{*}{ UniSTS:279053 } & \multirow{2}{*}{$\begin{array}{l}12 \mathrm{H} 14 ; 12112 ; 12 \mathrm{~J} 14 ; \\
12 \mathrm{~K} 14 ; 120 \mathrm{P} 21\end{array}$} \\
\hline & & R: ATCAGAAACACAAGCTGCTCCT & & & \\
\hline \multirow[t]{2}{*}{ S002 } & \multirow[t]{2}{*}{ ZBTB22 } & F: TCCTACGACTTACTCCCTCC & \multirow[t]{2}{*}{250} & \multirow[t]{2}{*}{ UniSTS:66823 } & \multirow[t]{2}{*}{ 12112;12 J14;258 F9; 289 G18 } \\
\hline & & R: GGGTCAGGTGGTTGTAGTCT & & & \\
\hline \multirow[t]{2}{*}{ S003 } & \multirow[t]{2}{*}{ KIFC1 } & F: GAGACTGTCCGAGACCTGCT & \multirow[t]{2}{*}{1242} & \multirow[t]{2}{*}{ UniSTS:BV104878 } & \multirow[t]{2}{*}{170 G9;217 M14;289 G18 } \\
\hline & & R: CTGTGACTACGCGACGAGC & & & \\
\hline \multirow[t]{2}{*}{ S004 } & \multirow[t]{2}{*}{ Loc100139397 } & F: GGTCATCATGGAGGCAGTCT & \multirow[t]{2}{*}{756} & \multirow[t]{2}{*}{ Exon 6: NC_007324 } & \multirow[t]{2}{*}{$19 \mathrm{H} 17$} \\
\hline & & R: CGTTCTCCTAAGCCATATGC & & & \\
\hline \multirow[t]{2}{*}{ S005 } & \multirow[t]{2}{*}{ BAK1 } & F: CATTGCATGGTGCTAACCGA & \multirow[t]{2}{*}{293} & \multirow[t]{2}{*}{ Exon 6: NC_007324 } & None \\
\hline & & R: CAAGCTCAGCCTTCCAGAAC & & & \\
\hline S006 & IHPK3 & F: ATGTATGAGAGCTTGGCACG & 1000 & UniSTS:267905 & 212D3 \\
\hline & & R: TCAGCTTGTACTCTTCCAGGG & & & \\
\hline S007 & LEMD2 & F: ACGTCTACCGCAACAAGCTG & 227 & ENSBTAE00000168818: Exon 1 & None \\
\hline & & R: GTCTCCGATGTCACCGTAGG & & & \\
\hline S008 & Loc790333 & F: GACTGCGAGGTGCCGAAGAA & 776 & Exon & 94 M24;114B22 \\
\hline & & R: GTGGACGGCTACACCTGCAA & & & \\
\hline S009 & HMGA1 & F: CTCATGCTCTCATTCGGACA & 625 & ENSBTAE00000364012: Exon 6 & 57 M5 \\
\hline & & R: CAGAACAGGAGGCAATGAGG & & & \\
\hline S010 & NUDT3 & F: TGAAGTGGAGAGCCTCACAA & 688 & ENSBTAE00000213256: Exon 5 & 14E10;300 G8 \\
\hline & & R: CTTCTCAGCAGACGATGGAC & & & \\
\hline S011 & COX5B & F: GTCTCCGTGGTGCGCTCTAT & 324 & ENSBTAE00000098033: Exon 1,2 & 130 G21;130 M2;170 K16 \\
\hline & & R: GGTGTGGCACCAGCTTGTAA & & & \\
\hline S012 & PACSIN1 & F: AAGCCAGCAACAGTAGCAGC & 683 & ENSBTAE00000336066: Exon 10 & 253124 \\
\hline & & R: TCGTTACCTGGAGACCAAGC & & & \\
\hline S013 & C6orf106 & F: AGTGAGCGGCTGAGAGAGTT & 266 & ENSBTAT00000048861: Exon 1 & None \\
\hline & & R: AACTCGGAGATGAGCACGTC & & & \\
\hline S014 & SNRPC & F: CCAATGATGAGACCTCCTGC & 147 & ENSBTAT00000034155:Exon 6 & 119P19;157 K19;223 \\
\hline & & R: CAGAGTCACAGCACCATGAT & & & $\mathrm{N} / ; 22 / J 1 / 232 \mathrm{G} 24$ \\
\hline S015 & TAF11 & F: TGGATGTGTGTGAGAAGTGG & 561 & ENSBTAT00000022463: Exon 5 & 194 L19;215 J4;232 \\
\hline & & R: TCATGGTGGAGTATCACAGG & & & \\
\hline S016 & ANKSIA & F: CGAGGAATGGCCACAAAG & 894 & UniSTS:BV105378 & 124P23;320A1 \\
\hline & & R: ATCGGTCTTGCCAAACAAAG & & & \\
\hline S017 & TCP11 & F: ATCAGCGGATCCACTTGTTC & 373 & ENSBTAT00000022467: Exon 11 & 24D11 \\
\hline & & R: CTGGAGCTCACACACGAGGT & & & \\
\hline S018 & DEF6 & F: ACCACCAGCAGCTCCTTCAC & 496 & ENSBTAT00000036152: Exon 11 & $21 \mathrm{M13;6616;124} \mathrm{K16;}$ \\
\hline & & R: CCTGGCTTGCTTGTTGACTC & & & \\
\hline S019 & PPARD & F: GTTCCATGGTCACCTTCTCC & 353 & ENSBTAT00000023319: Exon 8 & 28D20;152A4 \\
\hline & & R: CCGTGAATCTCGCTTCTCTT & & & \\
\hline SO20 & TEAD3 & F: CCCATCACAGCTGGATTTTA & 145 & UniSTS:180986 & None \\
\hline & & R: AAATGAAGTACTGTGCCCCC & & & \\
\hline S021 & Loc540812 & F: TGCACTGCAACTTCCTGAAC & 263 & Exon & 95D10;119O20;158O6 \\
\hline & & R: GCACTGCAGGCTGACTATGA & & & \\
\hline S022 & SRPK1 & F: CAGACACTTACAGGACGTGG & 273 & ENSBTAT00000022396: Exon 11 & 269D12;28515 \\
\hline & & R: TGAAGACTGGCACATCATGG & & & \\
\hline
\end{tabular}


Table 1 Comparative bovine primers used for identification of the positive ovine BAC clones in the genome region between MHC Class Ila and IIb* (Continued)

\begin{tabular}{|c|c|c|c|c|c|}
\hline \multirow[t]{2}{*}{ S023 } & \multirow[t]{2}{*}{ SLC26A8 } & F: ACATCAGCACCGTCAGTCACC & \multirow[t]{2}{*}{222} & \multirow[t]{2}{*}{ UniSTS:476830 } & \multirow[t]{2}{*}{$26 \mathrm{~A} 21 ; 121015$} \\
\hline & & R: AGGCGATAGAGGACAAACCACAC & & & \\
\hline \multirow[t]{2}{*}{ S024 } & \multirow[t]{2}{*}{ MAPK14 } & F: GAATGGATAACAAAACACTT & \multirow[t]{2}{*}{196} & \multirow[t]{2}{*}{ UniSTS:279403 } & \multirow[t]{2}{*}{$26 \mathrm{~A} 21 ; 121015$} \\
\hline & & R: CCTAAAATTAATTCACACTT & & & \\
\hline \multirow[t]{2}{*}{ S025 } & \multirow[t]{2}{*}{ MAPK13 } & F: AGAAGCTCAATGACAAGGCG & \multirow[t]{2}{*}{606} & \multirow[t]{2}{*}{ UniSTS:269171 } & \multirow[t]{2}{*}{ 121015;154 M16 } \\
\hline & & R: TTCCATTCGTCCACTGTGAG & & & \\
\hline \multirow[t]{2}{*}{ S026 } & \multirow[t]{2}{*}{ BRPF3 } & F: GACGCCTGCATCGTATTAGC & \multirow[t]{2}{*}{575} & \multirow[t]{2}{*}{ ENSBTAT00000017711: Exon 1} & \multirow{2}{*}{$\begin{array}{l}154 \text { M16;250 L24; } \\
\text { 278B11;281D9;300 J5 }\end{array}$} \\
\hline & & R: AGCCAGGTTGCAGATGTCAC & & & \\
\hline \multirow[t]{2}{*}{ S027 } & \multirow[t]{2}{*}{ PNPLA1 } & F: TCCTGAACGCTGTCAACCGA & \multirow[t]{2}{*}{449} & ENSBTAT00000055658: Exon 7 & 78 M7;153 F9;268E18; \\
\hline & & R: CAGGTGGCTGTGCAGGTGAT & & & 31904;337 K13 \\
\hline S028 & Loc790226 & F: CCATGACTCCGTAGACAAGA & 483 & Exon & $3 \mathrm{O} 16 ; 9 \mathrm{G} 2 ; 9 \mathrm{G} 3 ; 9 \mathrm{H} 8$ \\
\hline & & R: ACTGCCATAGCTACTGCTGC & & & \\
\hline S029 & KCTD20 & F: CGATGCAATCACTAAGCTGG & 834 & ENSBTAT00000027439: Exon 8 & None \\
\hline & & R: GCAGTTCTCATCCTTCGCAC & & & \\
\hline S030 & RPS4Y1 & F: TGCCAGCCTCTTGTCTCTCT & 430 & ENSBTAT00000036142: Exon 2 & 2A3;11 H24;63 N7; 82 \\
\hline & & R: TACACCTGAGGAGGCCAAGT & & & \\
\hline S031 & CDKN1A & F: GGATCGCTAAGAGCCGGACA & 861 & ENSBTAT00000011001: Exon 3 & None \\
\hline & & R: GGCAGTCGCTGCTTGAGGTA & & & \\
\hline S032 & PPIL 1 & F: AATGGTCAATGCGCCTGCTT & 888 & ENSBTAT00000003071: Exon 4 & $30017 ; 139 \mathrm{K9} ; 198$ \\
\hline & & R: CACCAACGGCAGCCAGTTCT & & & M20;271C5 \\
\hline S033 & Pl16 & F: CCTAGCAACAGAAGCCTCAA & 461 & ENSBTAT00000002703: Exon 5 & 54024 \\
\hline & & R: AGGCCAAGATCTCACTGCAA & & & \\
\hline S034 & FGD2 & F: CACCTTGGTGACCAACATTC & 414 & ENSBTAT00000018834: Exon 16 & 304 K7;318117 \\
\hline & & R: TCAGGCCAGCTCTACACCTT & & & \\
\hline S035 & PIM1 & F: AAGCACGTGGAGAAGGACCG & 490 & UniSTS:463218 & None \\
\hline & & R: GACTGTGTCCTTGAGCAGCG & & & \\
\hline S036 & TBC1D22B & F: CTGTCCACCACTCCATGTCT & 539 & ENSBTAT00000018938: Exon 13 & 5 K4;26A20;49B1;98 G9 \\
\hline & & R: GGACATTCGGACGTGTAACT & & & \\
\hline S037 & RNF8 & F: TCTGAATGGTGTCTGGCTGA & 708 & ENSBTAT00000010959: Exon 3 & None \\
\hline & & R: TTCTCGAGCTGCTCCACTCT & & & \\
\hline S038 & Loc509620 & F: AGTGGCACACCGAAGCTC & 666 & UniSTS:267349 & 25P1;103D16;207 \\
\hline & & R: AACTTCCTCTTGAAGCTITTGC & & & \\
\hline S039 & C23H6orf129 & F: GGCAAGAGAACCGCAAGAAC & 281 & ENSBTAT00000016009: Exon 4 & 25P1;103D16 \\
\hline & & R: GCACGAAGTCCTTCTGGAGC & & & \\
\hline S040 & MDGA1 & F: TCTTGGCGTTGCAGAGATGA & 228 & ENSBTAT00000047505: Exon 16 & None \\
\hline & & R: TGTGCGTGTGTCGAACAACC & & & \\
\hline S041 & ZFAND3 & F: CGATTGGTTTAATTITITITITCA & 200 & UniSTS:34520 & 159 K21;185 L24;235B3 \\
\hline & & R: TGTGAAGTTTGTTAAATGTAAGGAA & & & \\
\hline S042 & BTBD9 & F: GATAGGTCTTACGCTGTTAG & 155 & UniSTS:279369 & None \\
\hline & & R: GAATGTACAGAATAGAAGTG & & & \\
\hline S043 & Loc781915 & F: AACCTCAAGTGCCTCTCCAG & 714 & Exon & 67D11;70 N21;76E1; \\
\hline & & R: AACAAGTGTAGCCAGCCATC & & & \\
\hline$\overline{S 044}$ & GL01 & F: GATAGGTCTTACGCTGTTAG & 155 & UniSTS:279369 & None \\
\hline & & R: GAATGTACAGAATAGAAGTG & & & \\
\hline S045 & Loc525414 & F: GAAGAAGAGGTGATCGGTGTAGAG & 216 & UniSTS:476833 & 8 J2;13E21;24 K16; 24 \\
\hline & & R: TTTCTCCTTCCCATACATTTCTGTG & & & \\
\hline
\end{tabular}


Table 1 Comparative bovine primers used for identification of the positive ovine BAC clones in the genome region between MHC Class Ila and IIb* (Continued)

\begin{tabular}{|c|c|c|c|c|c|}
\hline \multirow[t]{2}{*}{ S045b } & \multirow[t]{2}{*}{ GLP1R } & F: CGAGTGTGAGGATTCCAAGC & \multirow[t]{2}{*}{418} & \multirow[t]{2}{*}{ Exon 4,5 and intron } & \multirow[t]{2}{*}{80 G15;138P3 } \\
\hline & & R: GTAGCCCACCGTGTAGATGA & & & \\
\hline \multirow[t]{2}{*}{ S046 } & \multirow[t]{2}{*}{ C23H6orf64 } & F: GTCACAGCCACCATGGAGTC & \multirow[t]{2}{*}{415} & \multirow[t]{2}{*}{ ENSBTAT00000001425: Exon 2} & \multirow{2}{*}{$\begin{array}{l}19 \text { F4;80 G15;138P3; } \\
\text { 156B12; } 336 \text { L24 }\end{array}$} \\
\hline & & R: CGCAAGCTGTTCTCAGTCAA & & & \\
\hline \multirow[t]{2}{*}{ S047 } & \multirow[t]{2}{*}{ KCNK5 } & F: CTCCGACTCTGTGCTGGTGA & \multirow[t]{2}{*}{774} & \multirow[t]{2}{*}{ ENSBTAT00000014756: Exon 5} & \multirow[t]{2}{*}{ None } \\
\hline & & R: TACCACGCCTTGTACCGCTA & & & \\
\hline \multirow[t]{2}{*}{ S048 } & \multirow[t]{2}{*}{ KCNK17 } & F: AGAGTCCAGGCTCCTTCTAT & \multirow[t]{2}{*}{493} & \multirow[t]{2}{*}{ ENSBTAT00000013646: Exon 5} & \multirow[t]{2}{*}{ None } \\
\hline & & R: CTGCTATCCTCAGAGTTCCA & & & \\
\hline \multirow[t]{2}{*}{ S049 } & \multirow[t]{2}{*}{ Loc100139627 } & F: GTGGAGGGAACCTGCGGCAC & \multirow[t]{2}{*}{344} & NC_007324.3: designed online & 3 L3;51O8;189 L22; \\
\hline & & R: AGGCCTCGGAAGAGCCCTGG & & & \\
\hline S050 & Loc100138924 & F: CTTGGTCTTGCGGGCCCCTG & 493 & NC_007324.3: designed online & 145 G9;146 H11 \\
\hline & & R: CCAGGCTCTAGCCCTGCCCA & & & \\
\hline S051 & DAAM2 & F: CAGGGAGTGCTCTCAAAGGTAAAGG & 307 & UniSTS:476834 & None \\
\hline & & R: TCCTCCAGCCTGACTTCTCCTTC & & & \\
\hline S052 & MOCS1 & F: GGTCCAGGAAGGCTGAAGTG & 661 & ENSBTAT00000013792: Exon 11 & None \\
\hline & & R: GAAGGACGGATGGCTATGGT & & & \\
\hline S053 & LRFN2 & F: TTGTCATACACGGCGGTCCT & 493 & ENSBTAT00000023907: Exon 1 & 77E2;220 J8;325 J12; \\
\hline & & R: AGCTGAGCCTCGACCACAAC & & & $325 J 13$ \\
\hline S054 & UNC5CL & F: TGACCAACGAGCAGCCACAC & 278 & UniSTS:476835 & None \\
\hline & & R: GCAGCAGGAGGAGCCAGAAG & & & \\
\hline S055 & NFYA & F: GCCGATGAAGAAGCTATGAC & 550 & ENSBTAT00000013080: Exon 10 & 76 K24;118P22;136B19 \\
\hline & & R: CATGAGATGGAGCTTCCTTG & & & \\
\hline S056 & TREM2 & F: ACAACTCCTTGAAGCACTGG & 229 & ENSBTAT00000009568: Exon 2 & 86A4;178 L4;208 M19; \\
\hline & & R: TGGAGGCTCTGGCACTGGTA & & & \\
\hline S057 & TREM1 & F: CATCATTCCTGCAGCATGTG & 515 & ENSBTAT00000023397: Exon 4 & $30 \mathrm{C} 8 ; 73 \mathrm{~K} 17 ; 75 \mathrm{~A} 11 ; 75121$ \\
\hline & & R: GGCTGTGCCAGGTCTTAGTT & & & \\
\hline S058 & LOC783024 & F: CTGAGGACCAAGGCCATGCT & 216 & Exon & None \\
\hline & & R: TGGTGTGGCACTGCAGGAAG & & & \\
\hline S059 & FOXP4 & F: AATTATCGCTCCAAGAGATTCCAC & 250 & UniSTS:384935 & 11211;144 K17;181 F9; \\
\hline & & R: CCCATCCTTGTCTCCTCTITACAT & & & \\
\hline S060 & $\mathrm{MDFI}$ & F: GCTGTGTCCACTGCATCTTG & 256 & ENSBTAT00000025763: Exon 4 & 70B14;166C6;181 J11; \\
\hline & & R: GGTCAGGAGGAGAAGCAGAG & & & \\
\hline S061 & $P G C$ & F: GAAATTCTCTGCTAAACCCCTTCA & 268 & UniSTS:385581 & 14 G18;2407;24010; 103 \\
\hline & & R: TCATCTAAGCAGAAACACCAGTAAATG & & & \\
\hline S062 & USP49 & F: GATGGAGTTCATGTAGCAGGTGTT & 260 & UniSTS:385828 & None \\
\hline & & R: GGAGCGCAAGAAGGAGGAG & & & \\
\hline S063 & BYSL & F: TCAGAGGACCTGGAAGTGGA & 538 & ENSBTAT00000013326: Exon 7 & 3 M12;98 J10;182 F10 \\
\hline & & R: CTCTCATGCACAGCAGTGGA & & & \\
\hline S064 & TAF8 & F: TGGAGGAAGGAACTTGGTCACAGAG & 228 & UniSTS:476836 & 103 M11;133 J10;146 L22 \\
\hline & & R: GGTGCTTGAGGTTCGTTGAGTTGAG & & & \\
\hline S065 & MGC137036 & F: GAAGCAGGACCGTGAGCAGA & 238 & ENSBTAT00000017035: Exon 2 & 100O15;117E7;133 J9; \\
\hline & & R: CTACGAGCGCCACAAGACCA & & & \\
\hline S066 & TRERF1 & F: GTGTGTCTGTTGCTGCGGTG & 643 & ENSBTAT00000020376: Exon 1 & 1O22;17 J12;79 H15; 81 \\
\hline & & R: TGGTCTAGGCTTGGCTGTTG & & & \\
\hline S067 & Loc786000 & F: TGGCAAGATGGCGGTGCCAG & 379 & NC_007324.3: designed online & 6P21;32P14;142C8; \\
\hline & & R: AGCAGCCTTGGCCCCACTCT & & & 162E5;195C23;227D22 \\
\hline
\end{tabular}


Table 1 Comparative bovine primers used for identification of the positive ovine BAC clones in the genome region between MHC Class Ila and IIb* (Continued)

\begin{tabular}{|c|c|c|c|c|c|}
\hline \multirow[t]{2}{*}{ S068 } & \multirow[t]{2}{*}{ UBR2 } & F: CTGCAAGCAACTGACCTCAC & \multirow[t]{2}{*}{169} & \multirow[t]{2}{*}{ ENSBTAT00000007833: Exon 2} & \multirow{2}{*}{$\begin{array}{l}\text { 6P21;129B6;162E5; } \\
\text { 163E23;177 M6 }\end{array}$} \\
\hline & & R: CCAACTCAGGATCTTCACCA & & & \\
\hline \multirow[t]{2}{*}{ S069 } & \multirow[t]{2}{*}{$\mathrm{PRPH} 2$} & F: GTAGTGGACTCCAGGAACTTCG & \multirow[t]{2}{*}{232} & \multirow[t]{2}{*}{ UniSTS:279013 } & \multirow{2}{*}{$\begin{array}{l}26 \mathrm{J6} 626 \text { L8;29 M14; } \\
\text { 127A7;134B12;177A2 }\end{array}$} \\
\hline & & R: ACCACAGAGTCACCTGCTGAGA & & & \\
\hline \multirow[t]{2}{*}{ S070 } & \multirow[t]{2}{*}{ Loc540169 } & F: ATGAAAGGGTCAGGCGAAC & \multirow[t]{2}{*}{130} & \multirow[t]{2}{*}{ UniSTS:94727 } & \multirow{2}{*}{$\begin{array}{l}\text { 144A13;164 L3;164 M2;164 } \\
\text { M3;172O18;185 N10 }\end{array}$} \\
\hline & & R: ACAGAGCCGCTAACCGTG & & & \\
\hline \multirow[t]{2}{*}{ S071 } & \multirow[t]{2}{*}{ CNPY3 } & F: GAACAGTGGTCTGGCAAGAA & \multirow[t]{2}{*}{214} & \multirow[t]{2}{*}{ ENSBTAT00000021132: Exon 10} & \multirow{2}{*}{$\begin{array}{l}98 \text { J16;172O18;185 } \\
\text { N10;18908;289 J21 }\end{array}$} \\
\hline & & R: GTTAGGCTCAGAGCTCGTCA & & & \\
\hline \multirow[t]{2}{*}{ S072 } & \multirow[t]{2}{*}{ CUL7 } & F: TTTCGACCTCGCTCTGAGTT & \multirow[t]{2}{*}{1,000} & UniSTS:270008 & 74C2;18908;289 J21; \\
\hline & & R: CTCCAGCATGTGCCAGTG & & & \\
\hline S073 & PTK7 & F: GACTCAGGAGCCTTCCAGTG & 531 & UniSTS:268417 & 54A6;127D14;142 L8; \\
\hline & & R: CTGTATTGCAGCTTCCGAGG & & & \\
\hline S074 & Loc540077 & F: CTGAATACCTGATCCGATGG & 417 & Exon & 54A6;142 L8;163O23; 204P7 \\
\hline & & R: GCATGTGCATGAGTAGGTCC & & & \\
\hline S075 & Loc786439 & F: GGCGTCTTTAATCAGGATTTGG & 200 & UniSTS:222501 & None \\
\hline & & R: AATCCAACACTTGAAACCGACA & & & \\
\hline S076 & ZNF318 & F: CTGTCTTCACTCGAAGCTCC & 438 & ENSBTAT00000013481: Exon 1 & 24 L23;66 G8;83 N5; \\
\hline & & R: AGCTCCTACTTCGTTCCTCC & & & 119 J9;162 F10 \\
\hline S077 & TJAP1 & F: GAGGACGAGGAAGAGCTGAA & 654 & ENSBTAT00000035977: Exon 12 & None \\
\hline & & R: CGTGCAGAGGATTGAAGGAG & & & \\
\hline S078 & POLH & F: GACAGCCACACACATAAGCA & 497 & ENSBTAT00000007900: Exon 11 & 68 F17;71 H18;74P6; \\
\hline & & R: GTCTCACAGAGTCGGACACG & & & \\
\hline S079 & MRPS18A & F: AGTCGTGAGACCACTGCAGC & 191 & ENSBTAT00000056429: Exon 6 & 115P10;176 M14; 233 \\
\hline & & R: AGGACCTCCTGAGAGCCTGA & & & \\
\hline S080 & VEGFA & F: GATCATGCGGATCAAACCTCACC & 326 & UniSTS:471318 & 12B17;12 H11;30 L7; \\
\hline & & R: CCTCCGGACCCAAAGTGCTC & & & 63B18;124 J8;249D14 \\
\hline S081 & MRPL14 & F: TCAGAACTGCTCCATTCACG & 182 & UniSTS:64809 & $117 \mathrm{J15}$ \\
\hline & & R: CAACAACGTGGTCCTCATTG & & & \\
\hline S082 & SLC29A1 & F: GGTGGTCTTTGAGCACGACT & 537 & UniSTS:207086 & None \\
\hline & & R: CCGGAACAGGAAGGAGAAG & & & \\
\hline S083 & AARS2 & F: CACTGGAAGCACTGCTGACC & 325 & ENSBTAT00000018232: Exon 22 & None \\
\hline & & R: GCAGCCAGAACAGCCATGTA & & & \\
\hline S084 & CDC5L & F: CCAACTCAGTGGAGGACCAT & 750 & UniSTS:267825 & 134E15;147|12 \\
\hline & & R: GGCTTTGTTTCTGGATTTGG & & & \\
\hline S085 & SUPT3H & F: CTTCTGCCTGGAACTTGCACTTG & 208 & UniSTS:476839 & 23P23;80P15;110 F4;5;6 \\
\hline & & R: TGCTTACTGTCTCCCACCTAGATTG & & & \\
\hline S086 & Loc536911 & F: TACCAGCCACCGAGACCAA & 309 & UniSTS:280406 & 9 G19;9 H22;9123;24; 59B8 \\
\hline & & R: AGAGGCTGTTTGACGCCATAG & & & \\
\hline S086b & CLIC5(BM1258) & F: GTATGTATTTTTCCCACCCTGC & 158 & UniSTS:56663 & 291115 \\
\hline & & R: GAGTCAGACATGACTGAGCCTG & & & \\
\hline S087 & ENPP4 & F: GAACCAGCTCACCAATGTGT & 595 & ENSBTAT00000004547: Exon 2 & 72 M13;74O6;127 F7; \\
\hline & & R: TCCTCTGCTTCACCACCTAA & & & \\
\hline S088 & RCAN2 & F: TCTITACTGTCTGAGCCACC & 132 & UniSTS:69107 & None \\
\hline & & R: TACACTCAGAGCTAGTTTGC & & & \\
\hline S089 & CYP39A1 & F: AGGTGATGGTGGCAACTATG & 200 & UniSTS:15671 & 57E15;181B7;202D23; \\
\hline & & R: CATGTGTCCATAATTTGATTGC & & & \\
\hline
\end{tabular}


Table 1 Comparative bovine primers used for identification of the positive ovine BAC clones in the genome region between MHC Class Ila and IIb* (Continued)

\begin{tabular}{|c|c|c|c|c|c|}
\hline \multirow[t]{2}{*}{ S090 } & \multirow[t]{2}{*}{ TDRD6 } & F: GAGTTCTTCCACCTGCCGTC & \multirow[t]{2}{*}{490} & \multirow[t]{2}{*}{ ENSBTAT00000013158: Exon 1} & \multirow{2}{*}{$\begin{array}{l}\text { 114B7;147E14;190 N9; } \\
329 \text { H12;350E16 }\end{array}$} \\
\hline & & R: ATACCTGAGCCATGCTCTCG & & & \\
\hline \multirow[t]{2}{*}{ S091 } & \multirow[t]{2}{*}{ Loc785478 } & F: TACGCCACCTACACACACAC & \multirow[t]{2}{*}{439} & \multirow[t]{2}{*}{ Exon } & \multirow{2}{*}{$\begin{array}{l}65 \text { L20;133 M1;211 N8; } \\
\text { 233B22;233O14 }\end{array}$} \\
\hline & & R: GACTGGTAGCTCCTGATCTG & & & \\
\hline \multirow[t]{2}{*}{ S092 } & \multirow[t]{2}{*}{ GPR116 } & F: CACATCCAGTGCTTATTCAT & \multirow[t]{2}{*}{302} & \multirow[t]{2}{*}{ ENSBTAT00000035930: Exon 18} & \multirow[t]{2}{*}{291 M9 } \\
\hline & & R: TAGACAGAGAAGTTGGCTTG & & & \\
\hline \multirow[t]{2}{*}{ S093 } & \multirow[t]{2}{*}{ GPR110 } & F: AGTGGACAGATACCGGCTGC & \multirow[t]{2}{*}{452} & \multirow[t]{2}{*}{ ENSBTAT00000028795: Exon 10} & \multirow[t]{2}{*}{ None } \\
\hline & & R: AGGTGTGGCCATGTGATGGA & & & \\
\hline \multirow[t]{2}{*}{ S094 } & \multirow[t]{2}{*}{ TNFRSF21 } & F: CAGAGCAGAAGGCACCAAGT & \multirow[t]{2}{*}{500} & ENSBTAT00000047874: Exon 11 & 118P16;351 H10 \\
\hline & & R: ATTGTCTGCCTCCTTGGTCC & & & \\
\hline S095 & LOC785024 & F: GGTTGTCAAGCCACTCGAAT & 611 & Exon & 14B7;79 L8;168 N8; 264 L6 \\
\hline & & R: CGGAGTATATGGCCAGTGTT & & & \\
\hline S096 & LOC512926 & F: AGAGCAGAAGGCACCAAGTC & 437 & Exon & 27A8;290 J19;351 H10 \\
\hline & & R: ACGCTCTGCATCTCATCACA & & & \\
\hline S097 & $C D 2 A P$ & F: TACCACAACACCAACTGCAT & 309 & UniSTS:278169 & $1 \mathrm{H} 10 ; 14 \mathrm{~A} 2 ; 75$ J19; \\
\hline & & R: TTACCGGGATCACAGAAACA & & & 114B12;151 J21;166 L22 \\
\hline S098 & GPR115 & F: CACAGTGGTGGCAGCAATAA & 490 & ENSBTAT00000003815: Exon 5 & None \\
\hline & & R: GAATAGAGTGCAATGCCGGT & & & \\
\hline S099 & OPN5 & F: CTACATCTGCCTGGCGGTCA & 287 & ENSBTAT00000021933: Exon 4 & 16718;228 M7 \\
\hline & & R: CATGGCTGCTATGGATCCGA & & & \\
\hline$S 100$ & MGC148542 & F: ACATTTTCTCCTTCTTTGGCTCC & 272 & UniSTS:133880 & 1A19;1B9;140A1; \\
\hline & & R: GATAGAGGATGACGACAAATGGC & & & \\
\hline S101 & Loc785693 & F: AGCCAGGTAGAGTTCCAATG & 518 & Exon & 17 K13;75E1;76B22; 103 F21 \\
\hline & & R: AGTCTCGGCAGTTACCTTGA & & & \\
\hline S102 & MUT & F: AGCAAAGCACATGCCAAAAT & 750 & UniSTS:279392 & 74 J7;8;86P12;252B10; \\
\hline & & R: TTCCCCAGAAGAAAGACAAC & & & \\
\hline S103 & Loc787783 & F: GGAATCATCAACCCAGTGAGAAAGC & 269 & UniSTS:476844 & 255 G2;266O16;274D6; \\
\hline & & R: CACACGGCGGCAGAAAGAGG & & & 288123 \\
\hline S104 & RHAG & F: GAATCGATGACCATCCATGC & 470 & ENSBTAT00000015012: Exon 4,5 & 53D7;173C22;186 L10; \\
\hline & & R: AGAAGGCTGGAACATGCGTA & & & \\
\hline S105 & Loc100138627 & F: AATGAATAGTATCCCCAATACCTGC & 150 & UniSTS:164033 & None \\
\hline & & R: GTCCACAAAACATTCTCCTITCC & & & \\
\hline S106 & TFAP2D & F: TAAGCTITCGGAGAAACCCA & 1422 & UniSTS:482175 & 5 K4; 139 L18;230 K5 \\
\hline & & R: CAGCAGCAAGACTCTCTGGA & & & \\
\hline$S 107$ & TFAP2B & F: TGCATGCTCCCTCCTCTC & 120 & UniSTS:71657 & 25D11;25 F24;142E22; \\
\hline & & R: CCTCGTCCAATTATGGTGCT & & & \\
\hline S108 & Loc100138859 & F: GGAGCACCACAGTACGTAAG & 561 & Exon & None \\
\hline & & R: GAGGTGTGCCTGTATTGCTA & & & \\
\hline S109 & Loc537895 & F: TTCTCTCAAATGATGAATATGCTTC & 270 & UniSTS:251053 & 56 J7;86O3;87 H23; \\
\hline & & R: GGACTATTCTATGCATGCCTCTC & & & \\
\hline S110 & IL17A & F: CACTCAGGCTGTATCAATGC & 591 & ENSBTAT00000002786: Exon 3 & 13B24;74A7;74E17; \\
\hline & & R: CAGCTGTGTCATGTACTCCA & & & \\
\hline S111 & MCM3 & F: TGTCCCGATTTGACCTTCTC & 515 & UniSTS:268664 & 69 G8;168E20;223C7; \\
\hline & & R: GTCATCAGGGCTGAAGTTGG & & & \\
\hline S112 & PAQR8 & F: TCTATGTCCTGTCCTCCATC & 447 & ENSBTAT00000035844: Exon 2 & 102 M1;160 L10 \\
\hline & & R: AGAAGAAGTAGGCACTGACC & & & \\
\hline
\end{tabular}


Table 1 Comparative bovine primers used for identification of the positive ovine BAC clones in the genome region between MHC Class Ila and IIb* (Continued)

\begin{tabular}{|c|c|c|c|c|c|}
\hline \multirow[t]{2}{*}{ S113 } & \multirow[t]{2}{*}{ TRAM2 } & F: TGTTCTACATCTTCATCGCCA & \multirow[t]{2}{*}{630} & \multirow[t]{2}{*}{ UniSTS:267311 } & \multirow[t]{2}{*}{ 13P23;53 J18;92C23 } \\
\hline & & R: ACCAGATCACCGAGCTGAGA & & & \\
\hline \multirow[t]{2}{*}{ S114 } & \multirow[t]{2}{*}{ TMEM14A } & F: CTACCCAAGAAACACTGTCGC & \multirow[t]{2}{*}{286} & \multirow[t]{2}{*}{ ENSBTAT00000006857: Exon 6} & \multirow{2}{*}{$\begin{array}{l}\text { 2C18;31C1;139B24; } \\
\text { 183A23;280 K17 }\end{array}$} \\
\hline & & R: AGAGCATTCTATGAAGCCCG & & & \\
\hline \multirow[t]{2}{*}{$S 115$} & \multirow[t]{2}{*}{ ICK } & F: ACGGACTGGATCGCTAAGTA & \multirow[t]{2}{*}{627} & \multirow[t]{2}{*}{ ENSBTAT00000020711: Exon 14} & \multirow{2}{*}{$\begin{array}{l}\text { 2C18;76A8;77 G6; } \\
\text { 198C12;199 K7 }\end{array}$} \\
\hline & & R: CAGAACAGCACAGCGGTATT & & & \\
\hline \multirow[t]{2}{*}{$S 116$} & \multirow[t]{2}{*}{ GCM1 } & F: AGCTGTCCAACTGCCTCCTG & \multirow[t]{2}{*}{363} & \multirow[t]{2}{*}{ ENSBTAT00000010709: Exon 6} & \multirow{2}{*}{$\begin{array}{l}\text { 141A15;199 K7;230E24 } \\
31412\end{array}$} \\
\hline & & R: TGGGAAGGGGAGAAGTCGTA & & & \\
\hline \multirow[t]{2}{*}{$S 117$} & \multirow[t]{2}{*}{ ELOVL5 } & F: CTACAGCCACGAGACAGTTT & \multirow[t]{2}{*}{182} & \multirow[t]{2}{*}{ UniSTS:279336 } & \multirow{2}{*}{$\begin{array}{l}64 \text { N21;82O21;90C20; } \\
127 \text { J19;163 F13 }\end{array}$} \\
\hline & & R: GGTTTCAATCATTCTTTCAT & & & \\
\hline
\end{tabular}

* The bovine oligo primers were designed along the target bovine genomic sequence at an interval of $\sim 80-160$ kb between the two neighbor loci, depending on the availability of the DNA sequence that meet the primer selection criteria. A total of 119 pairs of primers were listed here.

columns. Random BAC clones from each of 496 permanent 384-well storage plates were duplicated onto a LuriaBertani (LB) agar plate for overnight growth at $37^{\circ} \mathrm{C}$, using a 384-pin Multi-Blot Replicator as tool for BAC clone duplication (V \& P Scientific, Inc., San Diego, CA). The overnight $E$. coli colonies were then harvested and pooled for plate $(n=496)$, row $(n=16)$, or column $(\mathrm{n}=24)$. The standard alkaline lyses methodology was adapted for isolation of the pooled BAC plasmid DNA and the resulting DNA was assembled into super plates for routine PCR screening [35]. The first dimension of the BAC clone pool consisted of 496 DNA samples, each representing one of $496 \mathrm{BAC}$ plates (P001-P496). The second and third dimension consisted of 16 and 24 DNA samples, respectively, for the pooled 16 rows (R01-R16) and 24 columns (C01-C24) of the random BAC clones.

To screen the BAC library using each of 119 pairs of comparative oligo primer pairs, the diluted DNA from each well of the super pool plates was used as a DNA template. The individual PCR reaction was adapted in a total of $10 \mu \mathrm{l}$ reaction volume with $50 \mu \mathrm{M}$ of dNTPs, $1.5 \mathrm{mM} \mathrm{Mg}^{++}, 0.2 \mu \mathrm{M}$ of each primer pair, $1 \times$ PCR buffer, and 0.1 unit of Tag DNA polymerase. The PCR products were resolved by $1.5 \%$ agarose gel electrophoresis and the specific PCR fragment band with the expected size indicated a potential positive $\mathrm{BAC}$ clone for the gene loci of oligo primers used. The exact location of the target clone in the BAC library was determined by sequential PCRs using the super row and super column DNA as templates, respectively.

\section{DNA fingerprinting and contig assembling}

DNA fingerprinting was performed to determine the overlapping relationship among the identified positive BAC clones [12]. DNA from the positive BAC clone was purified from host E. coli by QIAGEN column and subjected for complete restriction enzyme digestion using HindIII. The enzyme digested products were analyzed on 1\% TAE agarose gel electrophoresis for recoding of DNA fragment patterns. The fingerprinting images were captured with UVP Labworks System (UVP Inc., Upland, CA) for systematic analysis. Restriction fragment patterns were analyzed to identify overlapping BAC clones, which were then manually assembled into draft contigs based on the modified methods of Marra [36] and Soderlund [37].

\section{BAC-end sequencing}

BAC-end sequencing was performed for the selected clones to facilitate verification of the overlapping relationships of the BAC clones. The sequencing was performed on an ABI 3730X DNA analyzer at the core facilities of the Institute of Genetics and Developmental Biology, the Chinese Academy of Sciences. The oligo nucleotide primers used for the DNA sequencing were Copycontrol pCC1BAC vector-derived sequencing primer T7 (5'-TAATACGACTCACTATAGGG3'), pCC1/pEpiFOS RP-2 (abbr. RP2) (5'-TACGCCAAGC TATTTAGGTGAGA-3'), and pCC1/pEpiFOS RP-1(abbr. RP-1) (5'-CTCGTATGTTGTGTGGAATTGTGAGC-3'). The resulting sequences were analyzed for overlapping, and used as templates for oligo primer design. Based on the sequence data generated by BAC-end sequencing, PCR primers (Additional file 1: Table S1) were designed to amplify the common genetic loci in two overlapped BACs for confirmation. Sequence-Specific PCRs (SP-PCRs) were performed in $20 \mu \mathrm{l}$ system including approximately $2 \mathrm{ng}$ BAC DNA, 0.5 U Taq DNA polymerase, $0.1 \mathrm{mM}$ dNTPs, $1.5 \mathrm{mM} \mathrm{Mg}{ }^{++}, 0.25 \mu \mathrm{M}$ each primer, and $1 \times$ PCR buffer. When necessary, the PCR products were verified by cloning the fragments into a TA vector for verifying DNA sequencing.

\section{Assemble of the BAC clone contig}

A continuous BAC clone contig was eventually assembled based on the integrated results of DNA fingerprinting, 
BAC-end sequencing, and sequence specific PCR amplification of the common loci on the overlapping clones. Redundant BAC clones were removed from the assembly based on the necessity and the relative contribution of each overlapping BACs on the contig. Gaps in the contig were closed by the repeated cycles of PCR screening of BAC clones, DNA fingerprinting of additional BAC clones identified, BAC-end sequencing, and SP-PCR verification. Additional effort was made to link the existing BAC clone contig to the physical map constructed previously, for a complete physical map covering the entire ovine $\mathrm{MHC}$ including the autosome insertion between class IIa and IIb.

For comparison of the MHC structure and organization between sheep and other mammals, multiple comparisons were performed for the representative MHC and extended DNA sequences from human, chimpanzees, mouse, cattle, and sheep. Sequence data were downloaded from the NCBI database and other related public websites designated for the sheep genomic information.

\section{Results}

\section{Target BAC identification}

We successfully identified a total of 368 positive BAC clones for ovine chromosome 20 between MHC class IIa and IIb, utilizing bovine primers designed from the consensus genome region (Table 1). Out of 119 pairs of oligo primers designed, 92 pairs worked effectively to generate specific target gene fragments of the expected sizes. This approach resulted in the successful identification of positive ovine BAC clones in the target genome region, and the overall efficiency of comparative PCR reached $80 \%$. The relatively high rate of success for the comparative SP-PCR not only facilitated our mapping efforts, but also helped to confirm the homologous nature of $\mathrm{MHC}$ regions between bovine and ovine species.

Organization of $\sim 190,500$ random ovine BAC clones into three dimensional super DNA pool of rows $(n=16)$, columns $(\mathrm{n}=24)$, and plates $(\mathrm{n}=496)$ significantly increased the efficiency of PCR screening of the sheep BAC library (Figure 1). The whole BAC library of $8.4 \times$ genome equivalents was screened through with a maximum of $536(=496+16+24)$ PCR reactions, and a positive $\mathrm{BAC}$ clone could be frequently identified by as few as $136(=96+16+24)$ PCR reactions using the super pool DNA as templates. In addition, PCR-based BAC clone screening also helped to eliminate the need for hybridization-based screening using radioactive ${ }^{32} \mathrm{P}$ labeling.

\section{DNA fingerprinting and BAC-end sequencing}

The initial order of the positive BAC clones identified was successfully determined by inferring the overlapping relationships among the clones via DNA fingerprinting, using HindIII for restriction enzyme digestion of the
BAC clone DNAs (Figure 2). Out of 368 positive BAC clones subjected for the DNA fingerprinting, 185 clones with their overlapping relationships were successfully determined. The resulting BAC contig covered the entire autosome insertion region between the MHC class IIa and IIb. After removing the redundant clones, a total of 108 effective BACs were ordered to form an overlapping BAC contig (Additional file 1: Table S1).

For cross-checking of the clone order, BAC-end sequencing was performed for all overlapping BAC clones, and the sequences generated were used to design BAC-end oligo primers (Additional file 1: Table S1) for further verification of overlapping relationships. The sequences of 185 BAC-ends have been deposited into the NCBI database with the access number HR309252 through HR309068, corresponding to dbGSS ID 30164010 through 30163826.

\section{Cross verification and physical map assembling}

For additional cross-verification of the BAC clone orders, a total of 108 pairs of BAC-end oligo primers were designed for amplification by PCR of the common loci in two overlapping BACs (Figure 3). Verification PCR confirmed the results of DNA fingerprinting at a high level of accuracy. Out of the 108 primer pairs used, 103 produced the specific PCR products with the expected size, the overall success rate reached 95\% (Additional file 1: Table S1). An overlapping relationship between two BACs was further verified if the common target loci were detected from both BACs in the overlapped region. A total of five pairs of oligo primers failed to generate the specific PCR band, or failed to produce the PCR fragment at the expected size.

A complete physical map of a BAC clone contig for the ovine $\mathrm{MHC}$ region between class IIa and IIb was successfully assembled (Figure 4), based on the integrated results of DNA fingerprinting, BAC-end sequencing, and confirmation PCR of the BAC ends. The fully assembled physical map was composed of 108 effective ovine BAC clones organized into a continuous contig that covered the entire region between ovine MHC class IIa and IIb (Figure 4). Based on the results of DNA fingerprinting, no gaps exist in the constructed BAC clone physical map which spans approximately $14 \mathrm{Mb}$ genome region of ovine chromosome 20 , indicating the even distribution of BAC clones in the library we previously constructed.

\section{Discussion}

Using the comparative approaches, we successfully constructed a $14 \mathrm{Mb}$ BAC clone contig map for a region in ovine chromosome 20 that harbors the MHC. Comparison between the identified ovine BAC contig and the orthologous bovine genomic region showed that the two 


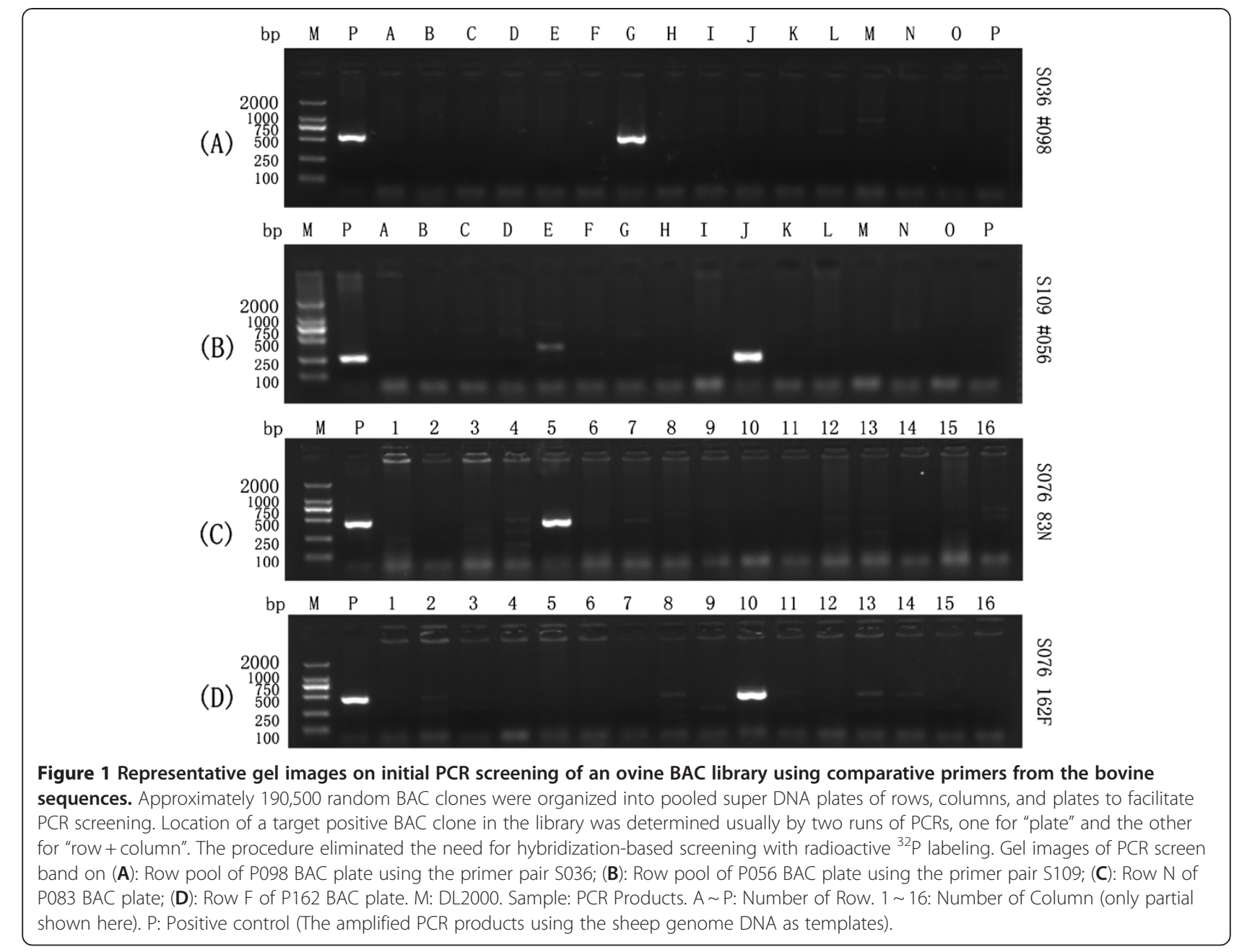

species share essentially the same genomic structure and organization for the entire inversion/insertion between MHC class IIa and IIb (Figure 5). For the available genetic loci generated via the SP-PCR and BAC-end sequencing, our results essentially confirmed the sheep genome sequence assembly presented by ISGC in the $\mathrm{MHC}$ region [33].

The physical map of ovine BAC contig we constructed helped to provide additional evidence to support the hypothesis that, there was an ancient chromosome rearrangement in the ancestor of ruminants which shaped the MHC structures currently observed in the ovine and bovine (Figure 5). It is obvious that the $\mathrm{MHC}$ region in human, mouse and chimpanzees is continuous with no interruption, but in bovine and ovine it is interrupted by a large piece of autosome insertion which divided MHC class II into IIa and IIb subregions (Figure 5). Given the fact of opposite loci order and orientation for the insertion region in ovine and bovine relative to those of human and mouse, it is highly possible that an event of genetic recombination occurred to the ancestor chromosome of ruminants, probably via chromosome looping and the subsequent crossover. This possibility was suggested by researchers previously [29,38].

Examination of the bovine DNA sequence from the public database showed that the total length of bovine $\mathrm{MHC}$ is $\sim 20 \mathrm{Mb}$, including the extended Class IIb region [34]. However, the total length of the orthologous ovine $\mathrm{MHC}$ was $\sim 14.3 \mathrm{Mb}$ as determined in this study, which is approximately $5.7 \mathrm{Mb}$ shorter than the $\mathrm{MHC}$ of bovine. On the other hand, the sequence of the same bovine region presented in the NCBI database is $\sim 18$ $\mathrm{Mb}$ in length (http://www.ncbi.nlm.nih.gov/projects/ mapview/maps.cgi?taxid=9913\&amp;chr=23). These discrepancies may not likely be resolved unless highly accurate sequence maps for the entire $\mathrm{MHC}$ regions become available.

The reliability of the ovine BAC contig map reported here is sufficiently high in theory, partially due to the fact that the DNA fingerprinting was utilized to infer the BAC clone orders, plus the results were cross-verified by both of the BAC-end sequencing and SP-PCR 


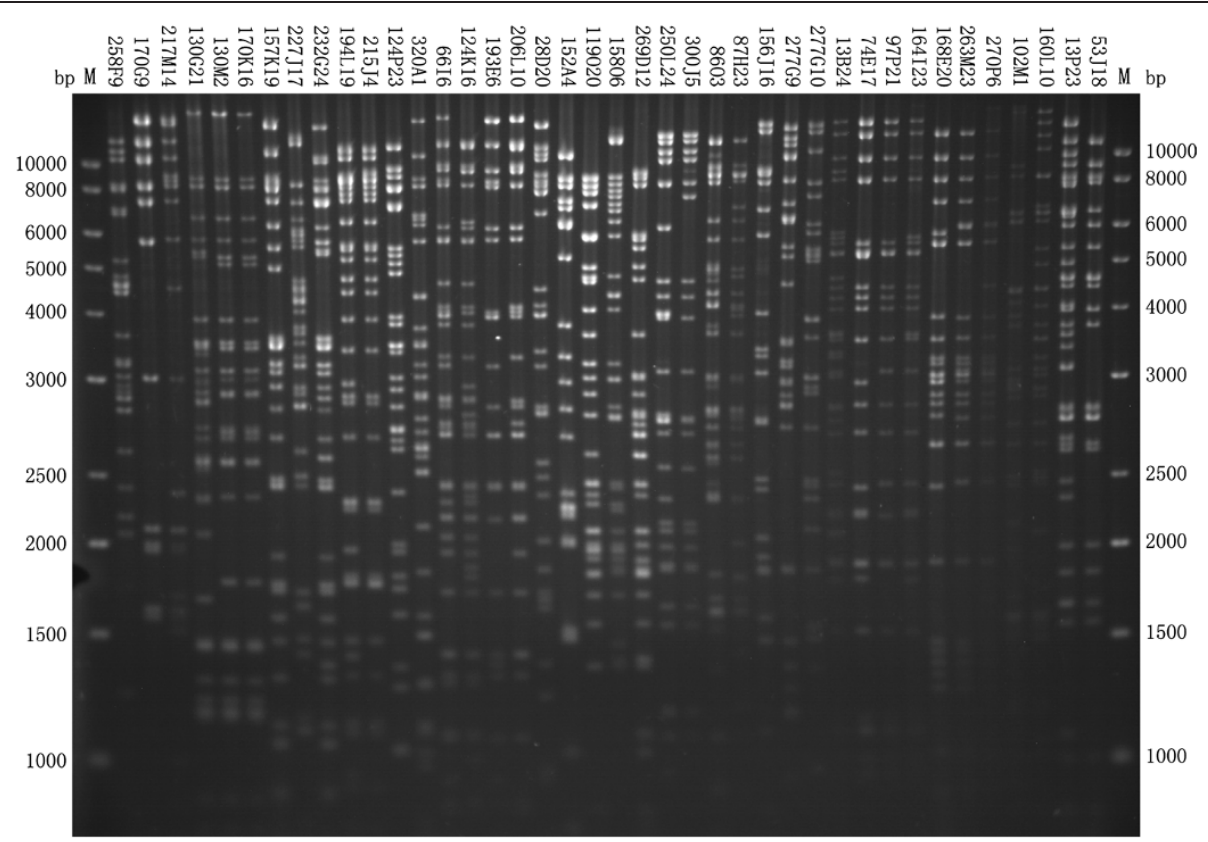

Figure 2 A representative image of DNA fingerprints of the positive BAC clones for determination of overlapping relationship. The positive BAC clones identified in the previous steps were digested with Hind III, followed by separation on a 1\% agarose gel in 1XTAE buffer. The gel was stained with Ethidium Bromide (EB) for photograph with a UVP Labworks system. M: Marker of DNA size standard (1 kb plus DNA ladder from Invitrogen, San Diego, CA, USA) with the base pair (bp) sizes indicated on both sides.

amplification of the target loci. However, it is not escaped from our attention that there are 5 out of the 108 overlapping locations in the BAC map where the SP-PCR failed to generate the expected PCR products between the overlapping BAC clones (data not shown). The significance of such failure in relation to the overall quality of the map remains to be determined. The possible explanations include the error in SP-PCR primer sequences, the high level of heterogeneity or polymorphism of the target locus involved, or the mistake in the interpretation of results of DNA fingerprinting.

Combined with our previous BAC physical map for the ovine MHC, we have now assembled a completed BAC clone physical map with the inversion/insertion region included (Additional file 2: Figure S1). The physical map will help to generate an ovine MHC sequencing map with a high level of accuracy, which in turn will

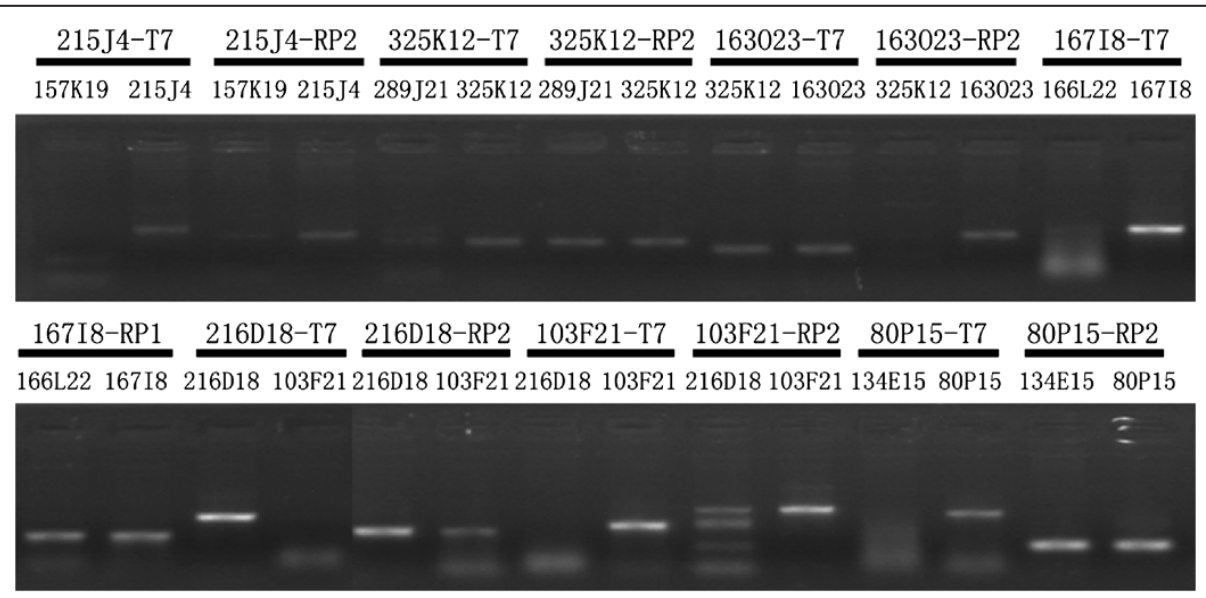

Figure 3 PCR verification of the overlapping relationship between pairs of overlapping BAC clones. Pairs of overlapped BAC clones were PCR amplified using a primer pair designed based on the BAC-end sequence. The markers above the black lines define the primer pairs and the ones below the lines are numbers of positive clones used as PCR templates. 


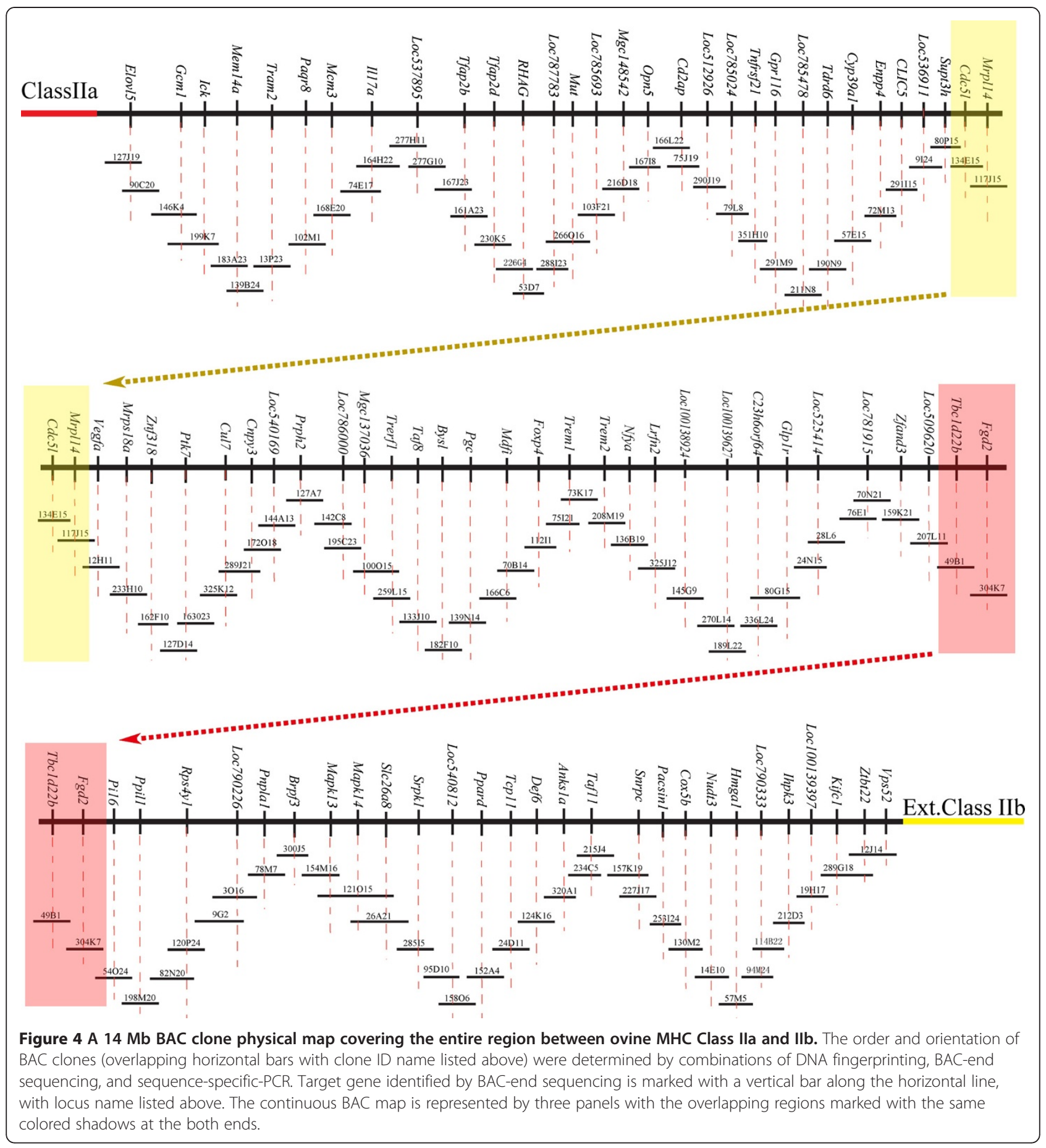

facilitate MHC functional studies and comparative MHC evolution studies in ruminants. DNA sequencing of the BACs is currently underway.

\section{Conclusion}

We constructed a high-density physical map for the sheep genome region between MHC class IIa and IIb via comparative approaches. A total of 108 effective ovine
BAC clones were selected to form a continuous BAC contig that covers the entire non-MHC insertion. The map spans approximately $14 \mathrm{Mb}$ in length, constituting $\sim 25 \%$ of ovine chromosome 20 . The entire ovine MHC region, including the autosome insertion for which the physical map has been constructed, is now fully covered by a continuous BAC clone contig. The accuracy of DNA sequences play vital roles in detailed SNP and 


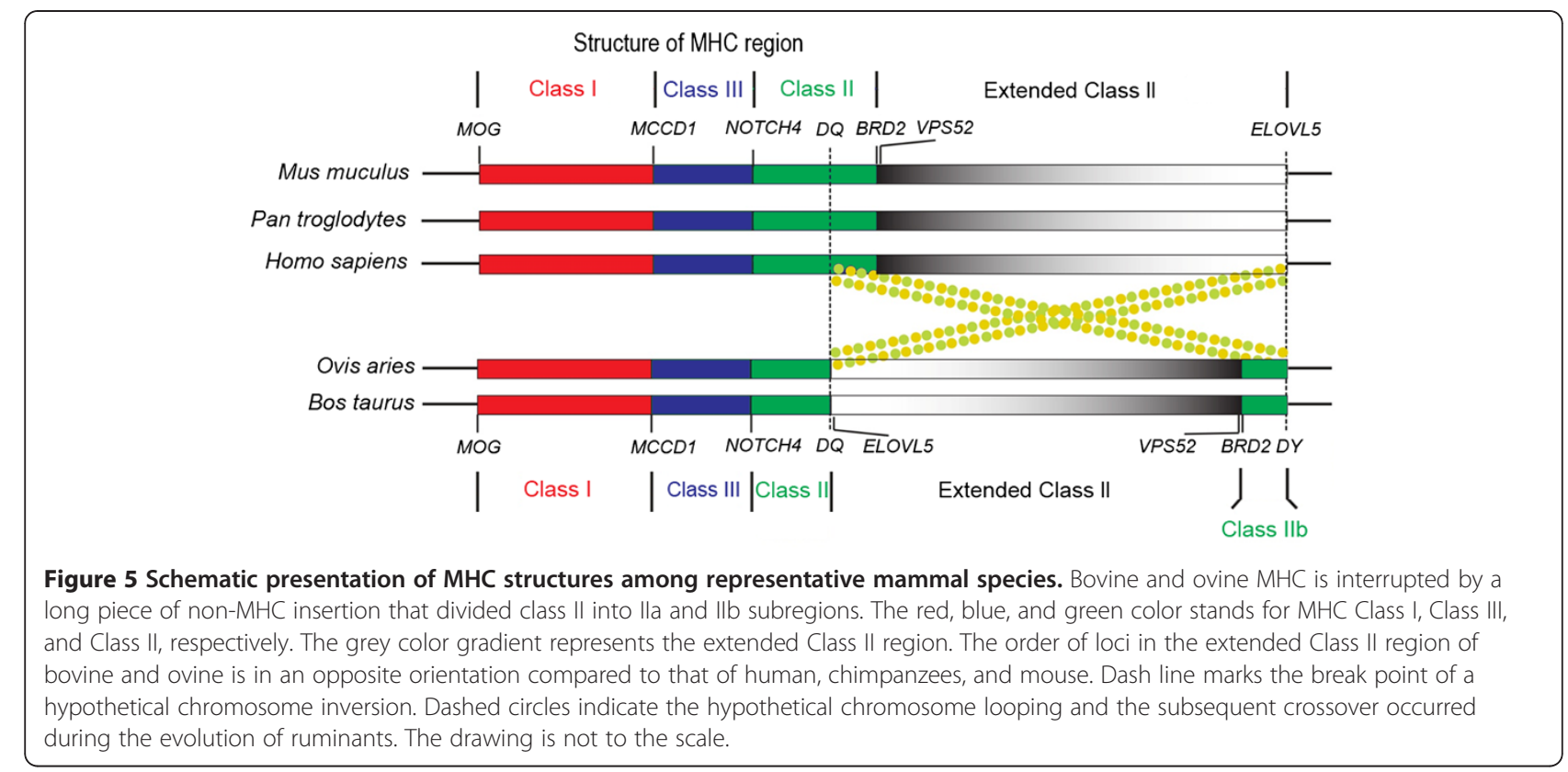

other functional studies of MHC genes, as well as for genome evolution studies. The physical map will help to generate ovine MHC sequencing map with a high level of accuracy, which in turn will facilitate MHC functional studies, as well as the comparative MHC evolution in ruminants.

\section{Additional files}

Additional file 1: Table S1. The ovine oligo primers used for verification of overlapping relationships of the positive BAC clones.

Additional file 2: Figure S1. A complete physical map of entire ovine $\mathrm{MHC}$ with the insertion region between class Ila and IIb included. Order and orientation of overlapping BAC clones were jointly determined by combinations of DNA fingerprinting, BAC-end sequencing, and sequence-specific PCR. Genes identified by BAC-end sequencing are marked with erect black lines, with their names listed above. A horizontal bar stands for individual BAC with its identification marked above. Red, purple and green color represent the MHC class I, class III, and class II, representatively.

\section{Competing interests}

Authors declare no conflict of interests.

\section{Authors' contributions}

GL carried out BAC library organization and SP-PCR screening. KL carried out DNA fingerprinting and contig assembling. SJ and GL performed oligo primer design and BAC-end sequencing. HL constructed the sheep BAC library. HB carried out data analysis. XC carried out certain verification experiments. PT and PZ carried out data cross checking. RM and JG supervised the studies and wrote the manuscript. All authors read and approved the final version of the manuscript.

\section{Acknowledgements}

The authors are very appreciative of the expert reviewers who helped to improve the quality of the manuscript significantly. This work was funded by research grants from National Natural Science Foundation of China (30125024; 30771148), Ministry of Science and Technology of China
(2006DFB33750; 2010CB530204), and China Ministry of Agriculture (2009ZX08008-005B).

\section{Author details}

${ }^{1}$ School of Life Sciences, Shihezi University, Xinjiang 832003, China. ${ }^{2}$ State Key Laboratory of Molecular Developmental Biology, Institute of Genetics and Developmental Biology, Chinese Academy of Science, Beijing 100101, China ${ }^{3}$ Institute of Veterinary Animal and Biomedical Sciences, Massey University, Palmerston North, New Zealand. ${ }^{4}$ Joint Research Center for Sheep Breeding and Developmental Biology, IGDB-Massey University, Massey, New Zealand. ${ }^{5}$ Graduate University of Chinese Academy of Sciences, Beijing 100149, China. ${ }^{6}$ Institute of Genetics and Developmental Biology, Chinese Academy of Science, Beijing 100101, China.

Received: 21 January 2012 Accepted: 3 August 2012

Published: 16 August 2012

\section{References}

1. Nei M, Rooney AP: Concerted and birth-and-death evolution of multigene families. Annu Rev Genet 2005, 39:121-152.

2. Spurgin LG, Richardson DS: How pathogens drive genetic diversity: MHC, mechanisms and misunderstandings. Proc Biol Sci 2010, 277(1684):979-988.

3. Trowsdale J: The MHC, disease and selection. Immunol Lett 2011, 137(1-2):1-8.

4. Bonneaud C, Richard M, Faivre B, Westerdahl H, Sorci G: An Mhc class I allele associated to the expression of T-dependent immune response in the house sparrow. Immunogenetics 2005, 57(10):782-789.

5. Dukkipati VS, Blair HT, Garrick DJ, Murray A: Ovar-Mhc-ovine major histocompatibility complex: role in genetic resistance to diseases. N Z Vet J 2006, 54(4):153-160.

6. Galindo RC, Ayoubi P, Garcia-Perez AL, Naranjo V, Kocan KM, Gortazar C, de la Fuente J: Differential expression of inflammatory and immune response genes in sheep infected with Anaplasma phagocytophilum. Vet Immunol Immunopathol 2008, 126(1-2):27-34.

7. Konnai S, Takeshima SN, Tajima S, Yin SA, Okada K, Onuma M, Aida Y: The influence of ovine MHC class II DRB1 alleles on immune response in bovine leukemia virus infection. Microbiol Immunol 2003, 47(3):223-232.

8. Mena A, Nichani AK, Popowych Y, loannou XP, Godson DL, Mutwiri GK, Hecker R, Babiuk LA, Griebel P: Bovine and ovine blood mononuclear leukocytes differ markedly in innate immune responses induced by Class A and Class B CpG-oligodeoxynucleotide. Oligonucleotides 2003, 13(4):245-259. 
9. Buitkamp J, Filmether P, Stear MJ, Epplen JT: Class I and class II major histocompatibility complex alleles are associated with faecal egg counts following natural, predominantly Ostertagia circumcincta infection. Parasitol Res 1996, 82(8):693-696.

10. Dukkipati VS, Blair HT, Garrick DJ, Murray A: 'Ovar-Mhc' - ovine major histocompatibility complex: structure and gene polymorphisms. Genet Mol Res 2006, 5(4):581-608.

11. Gruszczynska J, Brokowska K, Charon KM, Swiderek WP: Restriction fragment length polymorphism of exon 2 Ovar-DRB1 gene in Polish Heath Sheep and Polish Lowland Sheep. J Appl Genet 2005, 46(3):311-314

12. Liu H, Liu K, Wang J, Ma RZ: A BAC clone-based physical map of ovine major histocompatibility complex. Genomics 2006, 88(1):88-95.

13. Liu K, Zhang P, Gao J, Liu H, Li G, Qiu Z, Zhang Y, Ren J, Tan P, Ma RZ: Closing a gap in the physical map of the ovine major histocompatibility complex. Anim Genet 2011, 42(2):204-207.

14. Gao J, Liu K, Liu H, Blair HT, Li G, Chen C, Tan P, Ma RZ: A complete DNA sequence map of the ovine major histocompatibility complex. BMC Genomics 2010, 11(1):466-473.

15. Miltiadou D, Ballingall KT, Ellis SA, Russell GC, McKeever DJ: Haplotype characterization of transcribed ovine major histocompatibility complex (MHC) class I genes. Immunogenetics 2005, 57(7):499-509.

16. Mahdy EA, Makinen A, Chowdhary BP, Andersson L, Gustavsson I: Chromosomal localization of the ovine major histocompatibility complex (OLA) by in situ hybridization. Hereditas 1989, 111(1):87-90.

17. Escayg AP, Hickford JG, Bullock DW: Association between alleles of the ovine major histocompatibility complex and resistance to footrot. Res Vet Sci 1997, 63(3):283-287.

18. Ballingall KT, Fardoe K, McKeever DJ: Genomic organisation and allelic diversity within coding and non-coding regions of the Ovar-DRB1 locus. Immunogenetics 2008, 60(2):95-103.

19. Deverson EV, Wright $H$, Watson S, Ballingall K, Huskisson N, Diamond AG, Howard JC: Class II major histocompatibility complex genes of the sheep. Anim Genet 1991, 22(3):211-225.

20. Escayg AP, Hickford JG, Montgomery GW, Dodds KG, Bullock DW: Polymorphism at the ovine major histocompatibility complex class II loci. Anim Genet 1996, 27(5):305-312.

21. Scott $P C$, Choi $C L$, Brandon MR: Genetic organization of the ovine $M H C$ class II region. Immunogenetics 1987, 25(2):116-122.

22. Snibson KJ, Maddox JF, Fabb SA, Brandon MR: Allelic variation of ovine MHC class II DQA1 and DQA2 genes. Anim Genet 1998, 29(5):356-362.

23. van der Poel JJ, Groenen MA, Dijkhof RJ, Ruyter D, Giphart MJ: The nucleotide sequence of the bovine MHC class II alpha genes: DRA, DOA, and DYA. Immunogenetics 1990, 31(1):29-36.

24. Childers CP, Newkirk HL, Honeycutt DA, Ramlachan N, Muzney DM, Sodergren E, Gibbs RA, Weinstock GM, Womack JE, Skow LC: Comparative analysis of the bovine MHC class llb sequence identifies inversion breakpoints and three unexpected genes. Anim Genet 2006, 37(2):121-129.

25. Devilee P, Warnaar JN, Giphart MJ: MHC homology between various mammalian species at the DNA level: its relevance to MHC evolution. Exp Clin Immunogenet 1984, 1(2):90-98.

26. Qin J, Mamotte C, Cockett NE, Wetherall JD, Groth DM: A map of the class III region of the sheep major histocompatibilty complex. BMC Genomics 2008, 9:409.

27. Wright $H$, Ballingall $K T$, Redmond J: The DY sub-region of the sheep MHC contains an A/B gene pair. Immunogenetics 1994, 40(3):230-234.

28. Hickford JG, Ridgway HJ, Escayg AP: Evolution of the ovine MHC DQA region. Anim Genet 2000, 31(3):200-205.

29. Amills M, Ramiya V, Norimine J, Lewin HA: The major histocompatibility complex of ruminants. Rev Sci Tech 1998, 17(1):108-120.

30. Everts-van Der Wind A, Kata SR, Band MR, Rebeiz M, Larkin DM, Everts RE, Green CA, Liu L, Natarajan S, Goldammer T, et al: A 1463 gene cattle-human comparative map with anchor points defined by human genome sequence coordinates. Genome Res 2004, 14(7):1424-1437.

31. Maddox JF, Davies KP, Crawford AM, Hulme DJ, Vaiman D, Cribiu EP, Freking BA, Beh KJ, Cockett NE, Kang N, et al: An enhanced linkage map of the sheep genome comprising more than 1000 loci. Genome Res 2001, 11(7):1275-1289.

32. McShane RD, Gallagher DS Jr, Newkirk H, Taylor JF, Burzlaff JD, Davis SK, Skow LC: Physical localization and order of genes in the class I region of the bovine MHC. Anim Genet 2001, 32(5):235-239.
33. Archibald AL, Cockett NE, Dalrymple BP, Faraut T, Kijas JW, Maddox JF, McEwan JC, Hutton Oddy V, Raadsma HW, Wade C, et al: The sheep genome reference sequence: a work in progress. Anim Genet 2010, 41(5):449-453.

34. Elsik CG, Tellam RL, Worley KC, Gibbs RA, Muzny DM, Weinstock GM, Adelson DL, Eichler EE, Elnitski L, Guigo R, et al: The genome sequence of taurine cattle: a window to ruminant biology and evolution. Science 2009, 324(5926):522-528.

35. Osoegawa K, Woon PY, Zhao B, Frengen E, Tateno M, Catanese JJ, de Jong PJ: An improved approach for construction of bacterial artificial chromosome libraries. Genomics 1998, 52(1):1-8.

36. Marra MA, Kucaba TA, Dietrich NL, Green ED, Brownstein B, Wilson RK, McDonald KM, Hillier LW, McPherson JD, Waterston RH: High throughput fingerprint analysis of large-insert clones. Genome Res 1997, 7(11):1072-1084.

37. Soderlund C, Longden I, Mott R: FPC: a system for building contigs from restriction fingerprinted clones. Comput Appl Biosci 1997, 13(5):523-535.

38. Lewin HA, Russell GC, Glass EJ: Comparative organization and function of the major histocompatibility complex of domesticated cattle. Immunol Rev 1999, 167:145-158.

\section{doi:10.1186/1471-2164-13-398}

Cite this article as: Li et al:: A physical map of a BAC clone contig covering the entire autosome insertion between ovine MHC Class Ila and Ilb. BMC Genomics 2012 13:398.

\section{Submit your next manuscript to BioMed Central and take full advantage of:}

- Convenient online submission

- Thorough peer review

- No space constraints or color figure charges

- Immediate publication on acceptance

- Inclusion in PubMed, CAS, Scopus and Google Scholar

- Research which is freely available for redistribution

Submit your manuscript at www.biomedcentral.com/submit
C) Biomed Central 